\title{
Single incision gastrectomy for gastric cancer
}

\author{
Yun-Suhk Suh ${ }^{1}$, Hyuk-Joon Lee ${ }^{1,2}$, Han-Kwang Yang ${ }^{1,2}$ \\ ${ }^{1}$ Department of Surgery, ${ }^{2}$ Cancer Research Institute, Seoul National University College of Medicine, Seoul, Korea \\ Contributions: (I) Conception and design: YS Suh; (II) Administrative support: HJ Lee, HK Yang; (III) Provision of study materials or patients: YS \\ Suh; (IV) Collection and assembly of data: YS Suh; (V) Data analysis and interpretation: All authors; (VI) Manuscript writing: All authors; (VII) Final \\ approval of manuscript: All authors. \\ Correspondence to: Yun-Suhk Suh. Department of Surgery, Seoul National University College of Medicine, Seoul, Korea. Email: ysksuh@gmail.com.
}

\begin{abstract}
Based on rapid development of laparoscopic techniques and instruments, single-incision laparoscopic surgery (SILS) is expected to be the next step of "more" minimally invasive surgery. A few institutions gradually started to report their experience of single incision gastrectomy (SIG) for gastric cancer, but it is still difficult to accept that SIG can be performed as a popular procedure because of its technical difficulty. For wide adoption of SIG, the simplicity, safety and reproducibility of not only lymph node dissection but also reconstruction should be evaluated compared to a conventional procedure. With a thorough understanding of unique characteristics of SILS, single incision distal gastrectomy (SIDG) for early gastric cancer performed by laparoscopic surgeons with advanced technique is expected to have promising potential about excellent cosmesis, comparable morbidity and mortality in carefully selected patients. For appropriate adoption and steady progress of this state-of-the art surgery, scientific evaluation with healthy critics is necessary with new generation of SILS instrument platform.
\end{abstract}

Keywords: Single-incision laparoscopic surgery (SILS); gastric cancer; single incision distal gastrectomy (SIDG); minimally invasive surgery

Received: 13 February 2016; Accepted: 12 April 2016; Published: 18 May 2016.

doi: $10.21037 /$ tgh.2016.05.05

View this article at: http://dx.doi.org/10.21037/tgh.2016.05.05

\section{Introduction for single-incision laparoscopic surgery (SILS)}

Laparoscopic gastrectomy has been known to have several advantages, including less postoperative pain, better cosmesis, less inflammatory reaction, rapid recovery of bowel function, and fast recovery compared to conventional open surgery (1). For early gastric cancer, laparoscopic gastrectomy and lymph node dissection is considered safe and comparable procedure in terms of postoperative outcome even in large scale randomized clinical trial, and also expected to show promising long-term survival outcome (2-4). Technically, laparoscopic gastrectomy may be feasible and gradually standardized even for advanced gastric cancer (5).

Owing to rapid development of laparoscopic instruments and techniques, SILS could be expected to be the next step of "more" minimally invasive surgery and also becoming an academic issue recently (Figure 1).
The first adoption of SILS starts from the early 1990's (6). However, it took long time for this novel approach using single umbilical incision to be generalized because of technical difficulties with unstandardized surgical procedures and limitation of laparoscopic instruments. Especially, SILS has typical disadvantage including the lack of "triangulation" among instruments and camera scope, and extremely narrow range of motion around a single port, which may lead to collision among each instrument, uncomfortable or limited surgical view, unnecessarily larger umbilical incision and lack of assistance.

In terms of general surgery including appendectomy or cholecystectomy, recent several studies have reported that SILS is feasible and has similar surgical outcome without increasing significant complication (7-10). In terms of malignancy of digestive tract, SILS has been eagerly investigated in colorectal cancer and showed comparable outcome in a few studies including randomized clinical trial 


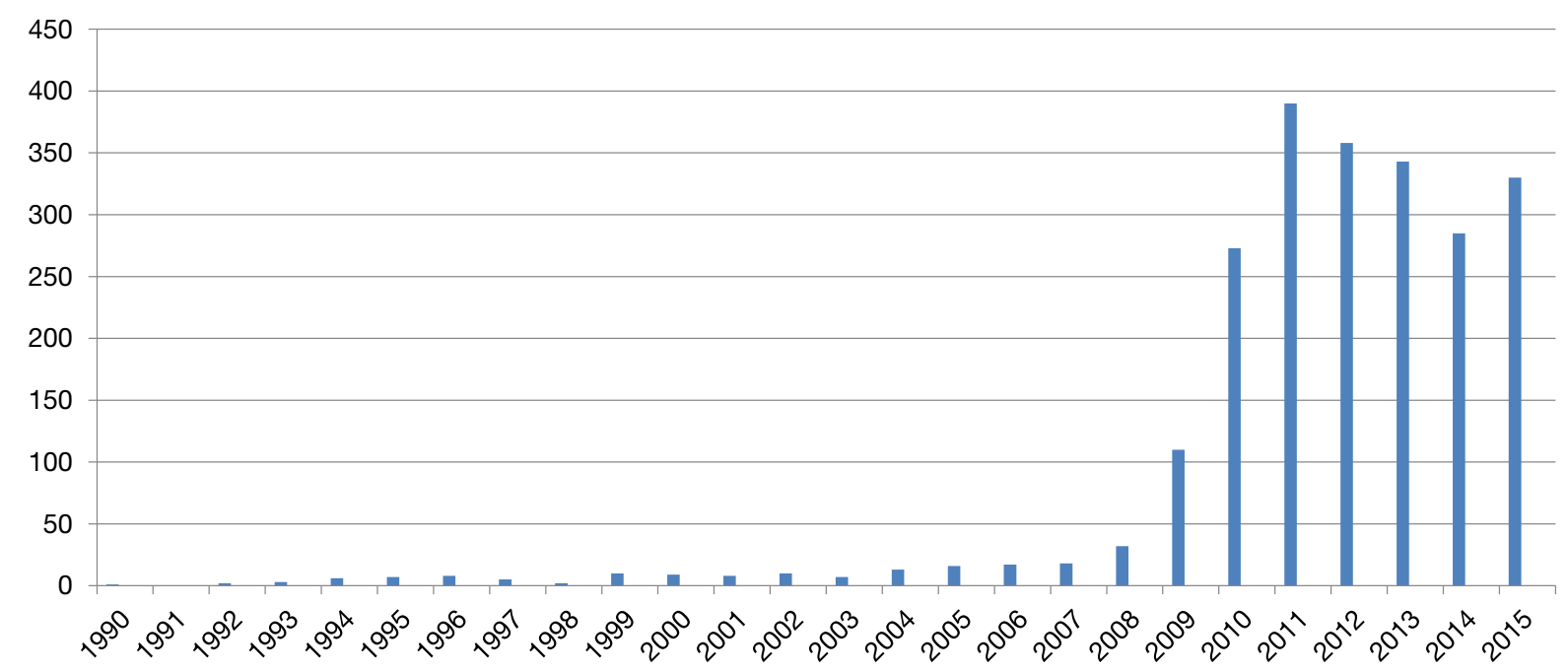

Figure 1 Time trends of the number of searched reports using keyword of "single incision laparoscopic" from 1990 to 2015 using PubMed as of January, 2016.

or matched retrospective study, even though the number of sample size was limited (11-14).

\section{Single incision distal gastrectomy (SIDG)}

For gastric cancer, SIDG with lymph node dissection was firstly reported in 2011 (15). Nowadays a few institutions gradually started to report their experience, but it is still difficult to accept that SIDG can be performed as more popular procedure (Table 1).

Gastric cancer surgeries consist of three major parts including lymph node dissection, gastrectomy, and reconstruction. Compared to other surgeries in gastrointestinal tract, there are more complicated guidelines for lymph node dissection around major nominated vessels and various ways of laparoscopic reconstruction in laparoscopic gastric cancer surgery which are continuously investigated and modified (26-28). To evaluate feasibility of SIDG for gastric cancer, we should consider these troublesome characteristics and its adequate solution in advance.

\section{Prerequisites}

Usually SILS requires at least 2.5 or $3 \mathrm{~cm}$ sized umbilical incision which is significantly much larger incision than conventional laparoscopic surgery. Therefore, many surgeons concerned that single wound complication including incisional hernia. However, resected stomach, several stations of lymph nodes and omentum consists of bulky specimen compared to relatively small appendix or gallbladder, or uniformly tubular structure of colon or rectum. To retrieve that bulky specimen without squeezing, current multiport laparoscopic gastric cancer surgery usually requires at least $2.5-3 \mathrm{~cm}$ sized incision, which means single incision laparoscopic gastric surgery does not require any extension of periumbilical wound and only omits other multi ports. Therefore, it may be more favorable situation for gastric surgery to adopt SILS compared to other intestinal surgeries. According to previous studies, there are several prerequisites to adopt SIDG as of now.

Firstly, in case of conventional rigid 30-degree laparoscope, energy device and camera scope almost always parallel to the surgical "point of interest" and very close between each other, which may lead to frequent collision and hinder the safe surgical view. To avoid this collision among grasper, energy device, stapler and camera system, the tip (camera) of the laparoscope should be located as much as far from other devices. Therefore, flexible laparoscope seems to be a nearly mandatory instrument. During the SILS, frequent movement of camera scope is more limited compared to conventional multiport laparoscopic surgery because of collision of instruments. Recently developed 3D scope system could be useful in terms of superior task efficiency because it can show more effective perspective and depth of field to operator, which means the decreased number of "air-catching" and less position change of camera scope (29-31). Secondly, the length and shape of instrument can be chosen depending 
Table 1 Previous historical reports of single incision distal gastrectomy for gastric cancer

\begin{tabular}{|c|c|c|c|c|c|c|c|}
\hline Year & Publication & Author & Country & Pure or additional & Anastomosis & $\mathrm{n}$ & Analysis \\
\hline 2014 & J Am Coll Surg (18) & Ahn et al. & Korea & Pure & $\begin{array}{l}42 \text { for Roux-en Y; } \\
8 \text { for Billroth I }\end{array}$ & 50 & $\begin{array}{l}\text { Comparative study (vs. } 50 \\
\text { multiports laparoscopic } \\
\text { distal gastrectomy) }\end{array}$ \\
\hline 2014 & J Am Coll Surg (19) & Ahn et al. & Korea & Pure & Roux-en Y & 22 & Single arm, feasibility \\
\hline 2014 & J Gastrointest Surg (20) & Omori et al. & Japan & With assistance & Billroth I, linear (intact) & 45 & Single arm, feasibility \\
\hline 2014 & Ann Surg Treat Res (21) & Ahn et al. & Korea & Pure & Roux-en Y & 14 & $\begin{array}{l}\text { Single arm, D2 LND with } \\
\text { mid pancreas mobilization }\end{array}$ \\
\hline 2012 & $\begin{array}{l}\text { Surg Laparosc Endosc } \\
\text { Percutan Tech (23) }\end{array}$ & Park et al. & Korea & $2 \mathrm{~mm}$ additional & Billroth I (delta anastomosis) & 2 & $\begin{array}{l}\text { Case report with D1 }+\beta \\
\text { LND }\end{array}$ \\
\hline 2012 & Surg Endosc (24) & Omori et al. & Japan & $2 \mathrm{~mm}$ additional & Billroth I (efficient purse string) & 20 & Single arm, feasibility \\
\hline 2011 & Surg Innov (25) & Ozdemir et al. & UK & Pure & Billroth II & 1 & $\begin{array}{l}\text { Case report with D1 }+\alpha \\
\text { LND }\end{array}$ \\
\hline 2011 & Surg Endosc (15) & Omori et al. & Japan & $2 \mathrm{~mm}$ additional & $\begin{array}{l}1 \text { for Roux-en Y and } 6 \text { for } \\
\text { Billroth I; (efficient purse string) }\end{array}$ & 7 & Single arm, feasibility \\
\hline
\end{tabular}

LND indicates lymphadenectomy.

on the situation. "Collision" is always problematic issue not only inside the peritoneal cavity but also outside the port in SILS. If possible, longer devices including energy device are much more useful to avoid collision among devices outside the port, because instruments longer than $40 \mathrm{~cm}$ makes wider gap between two hands of operator compared to conventional instruments. During the SILS, conventional linear grasper sometimes cannot effectively reach small lymph nodes around suprapancreatic area due to collision of energy device or protruded pancreas body with low lying umbilicus. For such cases, bending graspers are occasionally helpful to perform meticulous dissection of those lymph nodes. However, operator should be competent to perform "cross-handed manipulation" of instruments which is sometimes obviously required and also offers more various way of approach under limited surgical field. Lastly, operator should accustom himself to surgical procedure with minimal assistant, especially making good surgical field. To make good surgical field without any special assistant, frequent position change and subsequent traction using gravity should be utilized, and skillful usage of one left-handed grasper is important to make critical surgical field. However, obese patients who have much visceral fat are still not be a recommendable indication for SIDG because huge amount fat including possible metastatic lymph nodes is big hurdle to make clear surgical field without effective assistance.

\section{Lymphadenectomy}

For early gastric cancer located in lower one-third of the stomach, D1 or D1+ lymph node dissection is required according the Japanese gastric cancer treatment guideline (26). One of the most important stations is station \#6 around right gastroepiploic vessels. Because the root of right gastroepiploic vessels is slightly right side from the midline, the approach to the station \#6 is usually performed using left side approach which is preferred by some Japanese surgeons $(32,33)$. Using the gravity with right side upward position, dissection of station \#6 including soft tissue at 
the anterior surface of pancreas head can be performed safely. However, regarding the dissection of suprapancreatic lymph nodes, the neck and body of pancreas is sometimes significantly protruded, which make it difficult to approach the lymph nodes behind that pancreas using a straight energy based device from down the umbilicus. Especially, station \#11p is troublesome area for complete dissection if the proximal part of splenic artery is tortious. In our early experience, one patient was readmitted after discharge because of splenic artery pseudoaneurysm, and underwent reoperation with intensive care. This type of unique complication that might result from thermal damage by the various energy device was already reported even in a previous large scale study of laparoscopic distal gastrectomy with lymph node dissection $(34,35)$. In particular, during SIDG, use of an energy-based device should be minded with much more caution because there is no effective assistance to avoid possible thermal injury to adjacent tissues, including major vessels. Because dissection of \#11p is not mandatory for complete dissection in distal third early gastric cancer, strict indication for early gastric cancer and rather incomplete, safe exploration around station \#11p with careful usage of energy device might be more safe approach to adopt SIDG for gastric cancer as of now (26). As an alternative, mid-pancreas mobilization, somewhat aggressive mobilization for early gastric cancer, was recently introduced for complete dissection of \#11p LN (21).

\section{Reconstruction}

For the generalization of a new procedure such as SIDG, the simplicity, safety and reproducibility of not only lymph node dissection but also reconstruction should be evaluated compared to a conventional procedure (17). Regarding reconstruction, to consider procedure generalization, gastroduodenostomy or gastrojejunostomy should be equivocally evaluated after SIDG. Compared to Billroth II or Roux-en $\mathrm{Y}$ anastomosis using gastrojejunostomy, Billroth I anastomosis using gastroduodenostomy has been known to offer such advantages as more simple, less anatomical change after anastomosis, more physiological food passage and a lower incidence of internal hernia or adhesion and is consequently the most common anastomosis technique after distal gastrectomy in Korea and Japan, even in expert groups $(33,36)$.

Compared to gastroduodenostomy, gastrojejunostomy can be relatively simple procedure, and most of studies on the initial experience with SIDG preferred BII or Roux-en Y reconstruction using gastrojejunostomy $(19,22,25)$. In laparoscopic surgery, gastroduodenostomy has been usually considered as a more difficult technique because of the limitation of the intracorporeal approach with a circular stapler as well as the narrow working space around the duodenal stump. One of the well-established intracorporeal gastroduodenostomy, Delta-shaped anastomosis still requires advanced assistance because that assistant usually manipulates remnant stomach as well as staplers for reconstruction itself (37-39). In addition, it is more difficult to expect such advanced-assistance dependent procedure in SIDG, and one more small assistance grasper is likely to result in more collision because it makes narrow port space more crowded. Therefore, there have been limited number of original experience or modification of Billroth I anastomosis after SIDG, and reproducibility of gastroduodenostomy in pure SIDG still seems to be doubtful $(20,23,24)$. We reported our novel technique for gastroduodenostomy, "unaided delta-shaped anastomosis", without any additional port or intracorporeal assistance for pure SIDG, and also hope this technique will contribute to reproducible establishment of gastroduodenostomy in SIDG after validation (17).

\section{Outcome and understanding}

Regarding the outcomes of SIDG for gastric cancer, there have been only a few comparative studies (16-18). Twos studies comparing SIDG and multi (three or more) port totally laparoscopic distal gastrectomy (TLDG) reported similar operation time and comparable complication rate $(16,18)$. Regarding the oncologic outcome, the numbers of retrieved lymph nodes were similar between SIDG and TLDG in both studies. Interestingly these two studies showed similar operation time of SIDG $(144.5 \pm 35.4$ and $135.3 \pm 18.8$ minutes $)$ compared to TLDG $(140.3 \pm 36.3$ and $132.8 \pm 27.0$ minutes). However previous report of large scale randomized clinical trial performed by a "master class" group reported mean operation time of LADG as $184.7 \pm 55.0$ minutes, which is much longer than that of SIDG studies $(2,40)$. Considering standard deviation of 55.0 minutes, only limited population with shortest operation time in that trial may have similar operation time to SIDG studies. Therefore, recent limited reports of SIDG may have been understood as those results could be achieved only after the limited surgeons who have advanced skill for laparoscopic surgery carefully selected "surgeon-friendly" patients, and not be easily generalized for laparoscopic surgeons with insufficient 
experience as of now. In addition, even though previous studies of SIDG reported comparable morbidity and absence of open/multiport conversion, low competency for unexpected intraoperative accident in pure single port surgery still cannot be ignored. Single incision gastrectomy (SIG) usually requires least number of personnel, only one scopist and scrub nurse, in operating theatre. This procedure might receive any attention as "economically-efficient" surgery for a while $(41,42)$. However, low competency for intraoperative accidents including critical bleeding in SIDG is inevitable which is similar or more serious situation to that in transition period from open surgery to early laparoscopic surgery. In addition, considering the first step of standardization of surgical procedures are education and consensus, this dramatic advances in laparoscopic surgery has a tendency to longer distance trainees from the patient and especially assistant has none or least participatory role in SIG, which may result in much steeper learning curve for laparoscopic surgery in the future $(43,44)$.

To evaluate outcome of surgical procedure, the measurement of quality of life (QOL) is one of the most important issues, which will guide us from the comfort of previous medicine into a world that is less concrete and less controllable, but more human $(45,46)$. However, the objective and reproducible evaluation of QOL is not easy, especially in minimally invasive surgery or simple basic surgical procedure. Recently, for cholecystectomy, double-blinded RCT evaluating QOL between singleport cholecystectomy and conventional laparoscopic cholecystectomy was firstly reported (10). Using previously validated cosmesis and body image scores, and short form 36 health survey questionnaire SF-36, this study reported the statistical advantage of cosmesis and body image, higher QOL regarding emotional wellbeing, physical pain, physical health and mental health after postoperative 1 year, and less postoperative pain in single port cholecystectomy (47-49). However, quality of life in SIDG compared to TLDG was not comprehensively evaluated until now. Only regarding postoperative pain, previous two studies reported inconsistent results and difference of VAS score is less than 1 point in even significant result $(16,18)$. In the future, scientific evaluation of QOL will guide us to more reasonable assessment of outcome of this state-of-the art procedure.

\section{Single incision total gastrectomy}

The case report of pure single incision total gastrectomy

(C) Translational Gastroenterology and Hepatology. All rights reserved. for proximal early gastric cancer was firstly reported in 2014 (50). Collision of each instrument is expected to be more serious and making good surgical field also more difficult, however authors reported similar operation outcome compared to conventional multiport laparoscopic total gastrectomy. Obviously total gastrectomy has been known as a surgical technique with more significant morbidity and mortality compared to distal gastrectomy. Because this report is the only study based on single institution's early experience as of now, hasty adoption with distorted attraction to new technique should be postponed if it were not for enough experience of SIDG or other pure SILS.

\section{Conclusions}

As of now, SILS is one of the closest approaches to the ideal concept of "scarless" surgery. With a thorough understanding of unique characteristics of SILS, SIDG for gastric cancer performed by laparoscopic surgeons with advanced technique is expected to have promising positive potential about excellent cosmesis, comparable morbidity and mortality in carefully selected patients. For appropriate adoption and steady progress of this state-of-the art surgery, scientific evaluation with healthy critics is necessary with new generation of SILS instrument platform. Lastly, we have to keep in mind that the long term outcome of a large scale randomized clinical trial comparing "conventional" multiport laparoscopic distal gastrectomy and open distal gastrectomy for early gastric cancer is still waiting for us before SIDG (2).

\section{Acknowledgements}

The authors thank Dr. Seong-Ho Kong for his insightful comments of developing new surgical technique.

\section{Footnote}

Conflicts of Interest: The authors have no conflicts of interest to declare.

\section{References}

1. Yang HK, Suh YS, Lee HJ. Minimally invasive approaches for gastric cancer-Korean experience. J Surg Oncol 2013;107:277-81.

2. Kim W, Kim HH, Han SU, et al. Decreased Morbidity of 
Laparoscopic Distal Gastrectomy Compared With Open Distal Gastrectomy for Stage I Gastric Cancer: Short-term Outcomes From a Multicenter Randomized Controlled Trial (KLASS-01). Ann Surg 2016;263:28-35.

3. Takagi M, Katai H, Mizusawa J, et al. A phase III study of laparoscopy-assisted versus open distal gastrectomy with nodal dissection for clinical stage IA/IB gastric cancer (JCOG0912): Analysis of the safety and short-term clinical outcomes. J Clin Oncol 2015;33: abstr 4017.

4. Oh SY, Kwon S, Lee KG, et al. Outcomes of minimally invasive surgery for early gastric cancer are comparable with those for open surgery: analysis of 1,013 minimally invasive surgeries at a single institution. Surg Endosc 2014;28:789-95

5. Kim HI, Hur H, Kim YN, et al. Standardization of D2 lymphadenectomy and surgical quality control (KLASS02-QC): a prospective, observational, multicenter study [NCT01283893]. BMC Cancer 2014;14:209.

6. Pelosi MA, Pelosi MA 3rd. Laparoscopic supracervical hysterectomy using a single-umbilical puncture (minilaparoscopy). J Reprod Med 1992;37:777-84.

7. Markar SR, Karthikesalingam A, Thrumurthy S, et al. Single-incision laparoscopic surgery (SILS) vs. conventional multiport cholecystectomy: systematic review and meta-analysis. Surg Endosc 2012;26:1205-13.

8. Frutos MD, Abrisqueta J, Lujan J, et al. Randomized prospective study to compare laparoscopic appendectomy versus umbilical single-incision appendectomy. Ann Surg 2013;257:413-8.

9. Xu AM, Huang L, Li TJ. Single-incision versus threeport laparoscopic appendectomy for acute appendicitis: systematic review and meta-analysis of randomized controlled trials. Surg Endosc 2015;29:822-43.

10. Lurje G, Raptis DA, Steinemann DC, et al. Cosmesis and Body Image in Patients Undergoing Single-port Versus Conventional Laparoscopic Cholecystectomy: A Multicenter Double-blinded Randomized Controlled Trial (SPOCCtrial). Ann Surg 2015;262:728-34; discussion 734-5.

11. Katsuno G, Fukunaga $M$, Nagakari K, et al. Short-term and long-term outcomes of single-incision versus multiincision laparoscopic resection for colorectal cancer: a propensity-score-matched analysis of 214 cases. Surg Endosc 2016;30:1317-25.

12. Kim SJ, Ryu GO, Choi BJ, et al. The short-term outcomes of conventional and single-port laparoscopic surgery for colorectal cancer. Ann Surg 2011;254:933-40.

13. Huscher CG, Mingoli A, Sgarzini G, et al. Standard laparoscopic versus single-incision laparoscopic colectomy for cancer: early results of a randomized prospective study. Am J Surg 2012;204:115-20.

14. Poon JT, Cheung CW, Fan JK, et al. Single-incision versus conventional laparoscopic colectomy for colonic neoplasm: a randomized, controlled trial. Surg Endosc 2012;26:2729-34.

15. Omori T, Oyama T, Akamatsu H, et al. Transumbilical single-incision laparoscopic distal gastrectomy for early gastric cancer. Surg Endosc 2011;25:2400-4.

16. Suh YS, Park JH, Kim TH, et al. Unaided Stapling Technique for Pure Single-Incision Distal Gastrectomy in Early Gastric Cancer: Unaided Delta-Shaped Anastomosis and Uncut Roux-en-Y Anastomosis. J Gastric Cancer 2015;15:105-12.

17. Kim SM, Ha MH, Seo JE, et al. Comparison of single-port and reduced-port totally laparoscopic distal gastrectomy for patients with early gastric cancer. Surg Endosc 2015. [Epub ahead of print].

18. Ahn SH, Son SY, Jung do H, et al. Pure single-port laparoscopic distal gastrectomy for early gastric cancer: comparative study with multi-port laparoscopic distal gastrectomy. J Am Coll Surg 2014;219:933-43.

19. Ahn SH, Son SY, Lee CM, et al. Intracorporeal uncut Roux-en-Y gastrojejunostomy reconstruction in pure single-incision laparoscopic distal gastrectomy for early gastric cancer: unaided stapling closure. J Am Coll Surg 2014;218:e17-21.

20. Omori T, Masuzawa T, Akamatsu H, et al. A simple and safe method for Billroth I reconstruction in single-incision laparoscopic gastrectomy using a novel intracorporeal triangular anastomotic technique. J Gastrointest Surg 2014;18:613-6.

21. Ahn SH, Jung do H, Son SY, et al. Pure single-incision laparoscopic D2 lymphadenectomy for gastric cancer: a novel approach to $11 \mathrm{p}$ lymph node dissection (midpancreas mobilization). Ann Surg Treat Res 2014;87:279-83.

22. Kong J, Wu SD, Su Y. Translumenal single-incision laparoscopy radical gastrectomy with D2 lymph node dissection for early gastric cancer--primary experience with less invasive surgery in China. J Laparoendosc Adv Surg Tech A 2013;23:141-5.

23. Park do J, Lee JH, Ahn SH, et al. Single-port laparoscopic distal gastrectomy with $\mathrm{D} 1+\beta$ lymph node dissection for gastric cancers: report of 2 cases. Surg Laparosc Endosc Percutan Tech 2012;22:e214-6.

24. Omori T, Tanaka K, Tori M, et al. Intracorporeal circularstapled Billroth I anastomosis in single-incision laparoscopic distal gastrectomy. Surg Endosc 2012;26:1490-4.

25. Ozdemir BA, Thomas RL, Soon Y. Single- 
port laparoscopic subtotal gastrectomy with DI $\alpha$ lymphadenectomy. Surg Innov 2011;18:NP1-4.

26. Japanese Gastric Cancer Association. Japanese gastric cancer treatment guidelines 2010 (ver. 3). Gastric Cancer 2011;14:113-23.

27. Lee MS, Ahn SH, Lee JH, et al. What is the best reconstruction method after distal gastrectomy for gastric cancer? Surg Endosc 2012;26:1539-47.

28. Okabe H, Tsunoda S, Tanaka E, et al. Is laparoscopic total gastrectomy a safe operation? A review of various anastomotic techniques and their outcomes. Surg Today 2015;45:549-58.

29. Kong SH, Oh BM, Yoon H, et al. Comparison of twoand three-dimensional camera systems in laparoscopic performance: a novel 3D system with one camera. Surg Endosc 2010;24:1132-43.

30. Storz P, Buess GF, Kunert W, et al. 3D HD versus 2D HD: surgical task efficiency in standardised phantom tasks. Surg Endosc 2012;26:1454-60.

31. Wagner OJ, Hagen M, Kurmann A, et al. Three-dimensional vision enhances task performance independently of the surgical method. Surg Endosc 2012;26:2961-8.

32. Hiki N, Fukunaga T, Yamaguchi T, et al. The benefits of standardizing the operative procedure for the assistant in laparoscopy-assisted gastrectomy for gastric cancer. Langenbecks Arch Surg 2008;393:963-71.

33. Lee HJ, Shiraishi N, Kim HH, et al. Standard of practice on laparoscopic gastric cancer surgery in Korea and Japan: experts' survey. Asian J Endosc Surg 2012;5:5-11.

34. Kim MC, Kim W, Kim HH, et al. Risk factors associated with complication following laparoscopy-assisted gastrectomy for gastric cancer: a large-scale korean multicenter study. Ann Surg Oncol 2008;15:2692-700.

35. Seehofer D, Mogl M, Boas-Knoop S, et al. Safety and efficacy of new integrated bipolar and ultrasonic scissors compared to conventional laparoscopic 5-mm sealing and cutting instruments. Surg Endosc 2012;26:2541-9.

36. Jeong O, Park YK. Clinicopathological features and surgical treatment of gastric cancer in South Korea: the results of 2009 nationwide survey on surgically treated gastric cancer patients. J Gastric Cancer 2011;11:69-77.

37. Kanaya S, Kawamura Y, Kawada H, et al. The delta-shaped anastomosis in laparoscopic distal gastrectomy: analysis of

doi: $10.21037 / \operatorname{tgh} .2016 .05 .05$

Cite this article as: Suh YS, Lee HJ, Yang HK. Single incision gastrectomy for gastric cancer. Transl Gastroenterol Hepatol 2016;1:40. the initial 100 consecutive procedures of intracorporeal gastroduodenostomy. Gastric Cancer 2011;14:365-71.

38. Kanaya S, Gomi T, Momoi H, et al. Delta-shaped anastomosis in totally laparoscopic Billroth I gastrectomy: new technique of intraabdominal gastroduodenostomy. J Am Coll Surg 2002;195:284-7.

39. Okabe H, Obama K, Tsunoda S, et al. Advantage of completely laparoscopic gastrectomy with linear stapled reconstruction: a long-term follow-up study. Ann Surg 2014;259:109-16.

40. Villanueva MT. Gastric cancer: a master KLASS in laparoscopic gastrectomy. Nat Rev Clin Oncol 2014;11:119.

41. Lee YS, Kim JH, Moon EJ, et al. Comparative study on surgical outcomes and operative costs of transumbilical single-port laparoscopic appendectomy versus conventional laparoscopic appendectomy in adult patients. Surg Laparosc Endosc Percutan Tech 2009;19:493-6.

42. Love KM, Durham CA, Meara MP, et al. Single-incision laparoscopic cholecystectomy: a cost comparison. Surg Endosc 2011;25:1553-8.

43. Lee HJ, Yang HK. Quality Assurance of Gastric Cancer Surgery. J Korean Gastric Cancer Assoc 2005;5:79-88

44. Morgenstern L. A continuing challenge: the training of laparoscopic surgeons. Surg Innov 2005;12:289-90.

45. O'Boyle CA. Assessment of quality of life in surgery. Br J Surg 1992;79:395-8.

46. Schipper H. Why measure quality of life? Can Med Assoc J 1983;128:1367-70.

47. Ware JE Jr, Sherbourne CD. The MOS 36-item shortform health survey (SF-36). I. Conceptual framework and item selection. Med Care 1992;30:473-83.

48. Dunker MS, Stiggelbout AM, van Hogezand RA, et al. Cosmesis and body image after laparoscopic-assisted and open ileocolic resection for Crohn's disease. Surg Endosc 1998;12:1334-40.

49. Lind MY, Hop WC, Weimar W, et al. Body image after laparoscopic or open donor nephrectomy. Surg Endosc 2004;18:1276-9.

50. Ahn SH, Park do J, Son SY, et al. Single-incision laparoscopic total gastrectomy with D1+beta lymph node dissection for proximal early gastric cancer. Gastric Cancer 2014;17:392-6. 